\title{
Significance of the Building of National Mineral Deposit Database of China (2020)
}

\subsection{Providing Data for Smart Mineral Geological Survey of the China Geological Survey}

Data are fundamental strategic resources of a country and are considered as "diamond mines" in the twenty-first century. $\mathrm{Xi}$ Jinping, general secretary of the Communist Party of China (CPC) Central Committee, has pointed out that big data is the next stage of informatization development and has significant and profound impacts on the economic development, social progress, and people's lives worldwide. He mentioned that all countries in the world regarded the digital economy as an important driving force to achieve innovation and development. He also stressed that China has paid close attention to the development of the digital economy, pushed forward the digital economy to promote high-quality economic development, implemented the national big data strategy, and accelerated the construction of Digital China. The State Council of China issued the Action Framework for Promoting the Development of Big Data in 2015, marking that the big data for development officially became a national strategy of China. It also indicates that big data is growing into a new powerful engine driving economic transformation and development, a new opportunity to reshape the competitive advantages of the country, and a new point of economic growth that significantly affects the future information industry pattern. In terms of natural resource management, geologic data are national fundamental strategic resources and play an important role in promoting the transformation and development of the national economy.

Currently, the China Geological Survey is developing the Implementation Plan of Smart Mineral Geological Survey. Data is particularly important in smart prospecting prediction. China has carried out four rounds of mineral resource survey so far, and has achieved a series of result data. Furthermore, a large volume of data will be continually generated every year through the mineral geological survey. These data will serve as the base of the smart mineral survey. Only with the support of abundant data can enough sample data be available for the smart geological survey and prospecting. The Database 2020 will converge the achievements of all kinds of mineral resources in China, and thus lay an important database for smart mineral geological survey.

\subsection{More Efficiently Managing Mineral Resource Data of China}

The Database 2020 is intended to serve the needs of natural resource authorities, management departments of geological exploration and mineral development, mining enterprises, and scientific research institutes. With it, the large volume of complex mineral resource data obtained from diverse data sources can be efficiently managed, thus facilitating the understanding of the distribution, scale, and potential of mineral resources in China. Meanwhile, using this database, the mineral resource data of China can be converged, managed, developed, utilized, and put into service, and more convenient functions such as query, retrieval, and download can be provided. In this way, all kinds of result data of mineral resource survey are comprehensively managed, providing more strong data support and higher-level services for users.

\subsection{Improving the Up-to-Dateness of the Mineral Resource Data of China}

The Database 2002 had long been one of the databases serving the users the most frequently in the NGAC, thus holding great service value. However, since no necessary update and maintenance mechanisms were established when 
it was built, the mineral deposit data in the database has not been comprehensively and systematically updated for many years. This has seriously reduced the up-to-dateness of professional data.

In recent years, various mineral deposit databases have been submitted to the NGAC and the social demand for these databases has been gradually increased. Thus it was put on the agenda to build a more practical, more advanced mineral deposit data service system that can be continuously updated and shared based on the Database 2002. As various mineral resource databases were submitted to the NGAC, the original data in the Database 2002 can be updated by integrating the mineral data in these databases, thus improving the data up-to-dateness. So far, the mineral-related databases in the holdings of the NGAC include the result data of multiple national geological survey projects, such as the "Nationwide Mineral Resource Potential Assessment", the "Nationwide Mineral Resource Utilization State Survey", the "Superseding Resources Exploration in Resources Crisis Mines", and "Mineral Geological Survey Results". They provide the latest data and supplementary data for the building of a new edition of the National Mineral Deposit Database of China. Meanwhile, the Database 2020 will be updated based on the results of various mineral resource survey projects and integrate the data of all kinds of mineral deposits. Therefore, the up-to-dateness of the Database 2020 will be improved.

\subsection{Providing Comprehensive Data for Prospecting Prediction, Scientific Research, and Mineral Geological Survey}

In 2019, the NGAC organized over 20 mining enterprises, research institutes, and building material departments to propose and communicate their data demand face-to-face. This multi-industry demand survey provided specific and practical demand orientation for the NGAC to build the Database 2020. The project team members of the Database 2020 deeply understood the new changes in the demand for mineral resource data of prospecting professionals and scientific researchers, which laid a foundation for providing precise data services of mineral resources.

The Database 2020 was built with a view to better aggregate and integrate the thematic services of various mineral resource data and provide more precise service models. The purpose is to provide precise, high-level, comprehensive mineral resource data services for different fields and users involving prospecting prediction, scientific research, and mineral geological survey.

\subsection{A Typical Case of Building a Database Using Big Data Mining Technology Based on Geologic Data Holdings of NGAC}

Geologic data are also the collection of all kinds of geoscientific data and contain a large amount of geological knowledge, such as a large volume of mineral deposit data. To extract geological knowledge from the massive geologic data resources by technical means and to integrate them into a database will not only significantly lower the building cost of a geologic database but also make it possible to efficiently update and maintain the data in the database. This is the core innovative concept in the building of the Database 2020.

Mineral deposit information is one of the geological knowledge points contained in geologic data. According to the statistics of geologic data holdings of the NGAC, mineral exploration data account for more than $60 \%$ of all the data holdings, exhibiting the important position of mineral exploration in previous geological work in China. At the beginning of the twenty-first century, the China Geological Survey organized its geological survey branches in various provinces to build a mineral deposits database. As a result, the Database 2002 was built at a high cost. It was an important basic geologic database of China and effectively preserved the geological and mineral exploration data of China. However, with the advancement of society, science, and technology, geological work has been constantly developing and changing. As a result, the data items in the Database 2002 can hardly meet the need of social services, and it is necessary to further improve the database model of the Database 2002. Furthermore, no data update mechanism was established when the database was built. This makes it difficult to timely update the database and to guarantee the up-to-dateness of the mineral deposit data in the database after more than ten years of geological work. The Database 2020 has been built by extracting geological knowledge from the mineral deposit data contained in geologic data using the big data mining technology and then converging the knowledge into a database. Thus the building of the 
Database 2020 serves as a successful case of the concept of building a database by obtaining geological knowledge using big data mining technology.

\subsection{Providing Convenient Data Query and Retrieval Services for Users with Online Service Platform}

In the process of building a new edition of the National Mineral Deposit Database of China, phased results are obtained each year. So far, the Database 2020 has been built to provide social services. Furthermore, the online service platform of the Database 2020 has been recently developed and put into trial operation. The Database 2020 allows users to conveniently query mineral deposit data and filter the data by geographical division and metallogenic belts.

With the Database 2020, users can conduct online queries about all the basic information of mineral deposits stored in the database, including the name, longitude, latitude, mineral types, genetic type, scale, geological work degree, and geographical location. Users can query the mineral deposit information by the name and mineral type of mineral deposits and filter the information by administrative areas and user-defined conditions.

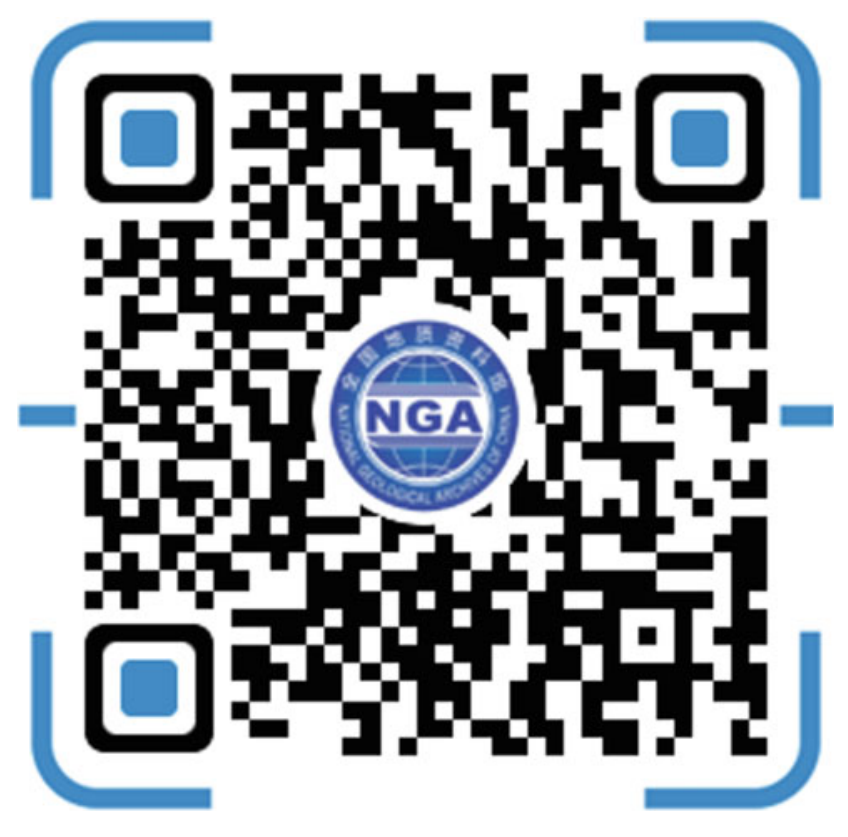

Fig. 3.1 Website of service platform app of the National Mineral Deposit Database of China (2020)

Website of the online service platform of Database 2020: https://data.ngac.org.cn/mineralresource/ (Fig. 3.1).
Open Access This chapter is licensed under the terms of the Creative Commons Attribution 4.0 International License (http:// creativecommons.org/licenses/by/4.0/), which permits use, sharing, adaptation, distribution and reproduction in any medium or format, as long as you give appropriate credit to the original author(s) and the source, provide a link to the Creative Commons license and indicate if changes were made.
The images or other third party material in this chapter are included in the chapter's Creative Commons license, unless indicated otherwise in a credit line to the material. If material is not included in the chapter's Creative Commons license and your intended use is not permitted by statutory regulation or exceeds the permitted use, you will need to obtain permission directly from the copyright holder.

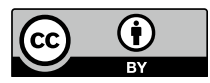

